\title{
SISTEM INFORMASI MANAJEMEN ASET PADA BPKAD PROVINSI NUSA TENGGARA BARAT BERBASIS WEBSITE DENGAN FRAMEWORK LARAVEL
}

\author{
(Asset Management Information System in BPKAD Province of West Nusa Tenggara \\ Based on Laravel Framework)
}

\author{
Ditha Nurcahya Avianty ${ }^{[1]}$, Andy Hidayat Jatmika ${ }^{[1]}$, Lalu Miftahul Ulum ${ }^{[2]}$ \\ ${ }^{[1]}$ Program Studi Teknik Informatika, Universitas Mataram \\ J1. Majapahit 62, Mataram, Lombok NTB, INDONESIA \\ ${ }^{[2]}$ UPTB Pelayanan Perbendaharaan Wilayah Pulau Lombok \\ BPKAD Provinsi NTB, Mataram, Lombok NTB, INDONESIA \\ Email: dithanurcahya55@gmail.com, andy@unram.ac.id, el.ulum82@gmail.com
}

\begin{abstract}
Abstrak
Perkembangan teknologi pada saat ini terjadi sangat pesat dan digunakan oleh banyak bidang seperti perkantoran, pendidikan, kesehatan, instansi pemerintahan dan lain-lain. Dalam perkembangannya, komputer digunakan untuk mengolah, menyimpan dan mencari data dengan cepat dan efisien untuk membantu pekerjaan manusia hingga dapat mengurangi terjadinya human error dan informasi yang dihasilkan akan lebih tepat sehingga meningkatkan kualitas kerja suatu perusahaan maupun instansi pemerintahan. Dalam pengelolaan aset di Badan Pengelolaan Keuangan dan Aset Daerah (BPKAD) Provinsi Nusa Tenggara Barat sendiri, proses pelaporan pengelolaan, dan monitoring stok barang dari tahun ke tahun masih dilakukan secara manual dan kurang efektif. Dengan adanya permasalahan tersebut, maka dibuatlah "Sistem Informasi Manajemen Aset pada Badan Pengelolaan Keuangan dan Aset Daerah Provinsi Nusa Tenggara Barat” berbasis website menggunakan framework Laravel untuk membantu pegawai BPKAD Provinsi NTB menjalankan pekerjaannya dengan lebih efisien. Pengujian dilakukan pada pihak BPKAD Provinsi NTB dengan metode Mean Opinion Score (MOS) dengan hasil bahwa 86,67\% responden setuju bahwa sistem informasi yang dibuat dapat membantu pegawai dan telah berjalan dengan baik.
\end{abstract}

Keywords: Sistem Informasi, Manajemen Aset, Website, Laravel, Mean Opinion Score

\section{Pendahuluan}

\subsection{Latar Belakang}

Pada saat ini, perkembangan teknologi sangat pesat dan digunakan oleh banyak bidang seperti perkantoran, pendidikan, kesehatan, instansi pemerintahan dan lain lain. Dalam instansi pemerintah, beberapa aktifitas sudah menggunakan komputer namun beberapa aktivitas seperti pengelolaan data aset barang keluar masuk dilakukan secara konvensional dengan media kertas. Dalam perkembangannya, komputer digunakan untuk mengolah, menyimpan dan mencari data dengan cepat dan efisien untuk membantu pekerjaan manusia hingga dapat mengurangi terjadinya human error dan informasi yang dihasilkan akan lebih tepat sehingga meningkatkan kualitas kerja suatu perusahaan maupun instansi pemerintahan.

Badan Pengelolaan Keuangan dan Aset Daerah Provinsi (BPKAD) Provinsi Nusa Tenggara Barat (NTB) adalah suatu badan/institusi yang merupakan gabungan dari sub Bagian Perlengkapan pada Biro Umum Sekretariat Daerah (Setda) Provinsi NTB dan eks Biro Keuangan Setda Provinsi NTB. BPKAD Provinsi NTB bertugas untuk memudahkan dalam menyelesaikan permasalahan aset maupun keuangan yang kompleks

Dalam pengelolaan aset di BPKAD Provinsi NTB sendiri, proses pelaporan pengelolaan, dan monitoring stok barang dari tahun ke tahun masih dilakukan secara manual dan kurang efektif. Hal ini berpengaruh terhadap kelengkapan dari data-data yang memiliki kemungkinan terdapat data barang yang lupa untuk didata dan hal lain yang dapat mempengaruhi kelengkapan data seperti data barang yang telah terpakai atau sisa stok barang yang ada. Dengan menggunakan sistem yang manual, akan menyulitkan pegawai dalam mengelola data-data tersebut, dimana data barang tersebut harus dicari satu persatu sehingga akan membutuhkan waktu yang sangat lama. Dengan adanya permasalahan tersebut, maka dibuatlah "Sistem Informasi Manajemen Aset pada Badan Pengelolaan Keuangan dan Aset Daerah Provinsi Nusa Tenggara Barat" yang diharapkan dapat membantu pegawai BPKAD Provinsi NTB mengelola data-data tersebut agar lebih efisien. 


\subsection{Tujuan dan Manfaat}

a. Tujuan.

Tujuan pembuatan sistem informasi manajemen aset yaitu membangun sistem informasi yang dapat mempermudah pencatatan pengelolaan aset barang di Badan Pengelolaan Keuangan dan Aset Daerah Provinsi Nusa Tenggara Barat

b. Manfaat.

Manfaat dari pembuatan sistem informasi manajemen aset adalah sebagai berikut:

1. Bagi instansi.

- Dapat mempermudah pegawai Badan Pengelolaan Keuangan dan Aset Daerah Provinsi Nusa Tenggara Barat dalam pencatatan pengelolaan aset

- Dapat menghemat ruang dari segi tempat maupun biaya

2. Bagi mahasiswa.

- Memberikan pengalaman kerja terhadap mahasiswa

- Mahasiswa dapat menerapkan ilmu-ilmu yang telah dipelajari pada saat kuliah untuk menyelesaikan masalah yang diberikan

\section{TINJAUAN PUSTAKa DAN DASAR TEORI}

\subsection{Tinjauan Pustaka}

Sistem informasi berbasis web sudah banyak diterapkan pada beberapa instansi karena kemudahannya bagi pegawai untuk mengelola data di instansi tersebut. Penelitian berjudul "Rancang Bangun Sistem Informasi Manajemen Aset pada Universitas Pamulang Berbasis Web" dibangun untuk memudahkan manajemen dalam mengelola aset agar menjadi lebih efisien, efektif, dan terstruktur. Berdasarkan hasil pengujian black box dan white box pada sistem, dapat diambil kesimpulan bahwa sistem manajemen aset yang telah dibangun memiliki fungsional yang baik dan bebas dari kesalahan serta memberikan hasil yang sesuai harapan [1].

Selain itu, pada penelitian dengan judul "Sistem Informasi Sewa Aset Dan Fasilitas Berbasis Web Pada Universitas Andalas", didapatkan hasil bahwa dengan adanya sistem informasi aset pencatatan pembayaran sewa dan fasilitas dapat disimpan berupa digital, mencari status penyewa dan fasilitas yang sudah membayar atau separuh membayar dapat menggunakan menu pencarian, sehingga waktu yang dibutuhkan untuk mencari data lebih cepat, merekap data transaksi keseluruhan membutuhkan waktu yang singkat dan data yang diperoleh benar, pimpinan dapat melihat kegiatan yang sedang berjalan dengan mudah [2]. Hal ini menunjukkan bahwa pembangunan sistem informasi manajemen aset akan membuat pengelolaan aset menjadi lebih efisien dan efektif.

Pemilihan framework Laravel untuk mengembangkan web didasarkan pada beberapa penelitian yang menggunakan framework ini. Penelitian pertama yang berjudul "Implementasi Sistem Informasi Akademik Berbasis Web Menggunakan Framework Laravel" menyimpulkan bahwa penggunaan framework Laravel dapat memenuhi semua kebutuhan dalam pengembangan sistem [3]. Penelitian selanjutnya yang berjudul "Penggunaan Framework Laravel Dalam Rancang Bangun Modul Back-End Artikel Website Bisnisbisnis.ID” didapatkan bahwa penggunaan framework Laravel lebih memudahkan pengembang karena syntax Laravel yang bersih dan fungsional serta library yang banyak dan mudah digunakan sehingga dapat mempercepat pembangunan sistem. Hasil pengujian yang dilakukan dengan menggunakan metode Black-Box testing didapati bahwa fungsi yang dibuat sudah sesuai dengan kebutuhan sistem [4].

\subsection{Dasar Teori}

a. Sistem Informasi

Sistem informasi adalah sistem yang disusun oleh satu atau beberapa sistem pengolahan data meliputi data, informasi, pengetahuan, dan kebijaksanaan [5]. Dalam sistem informasi terdapat proses atau aktivitas aktivitas yang akan mendukung aktivitas usaha dalam sistem organisasi.

b. Manajemen Aset

Manajemen aset didefinisikan sebagai sebuah proses pengelolaan aset (kekayaan) baik berwujud dan tidak berwujud yang memiliki nilai ekonomis, nilai komersial, dan nilai tukar, serta mampu mendorong tercapainya tujuan. Secara umum, siklus pengelolaan aset adalah tahapan yang harus dilalui dalam manajemen aset [6].

c. Use Case Diagram

Use case diagram menggambarkan fungsionalitas yang diharapkan dari sebuah sistem. Sebuah use case merepresentasikan sebuah interaksi antara aktor dengan sistem [7]. 


\section{d. Activity Diagram}

Activity diagram menggambarkan berbagai alir aktivitas dalam sistem yang sedang dirancang, bagaimana masing-masing alir berawal, decision yang mungkin terjadi, dan bagaimana mereka berakhir [7].

e. Class Diagram

Class diagram menggambarkan struktur dan deskripsi class, package dan objek serta hubungan satu sama lain seperti containment, pewarisan, asosiasi, dan lain-lain [7].

f. Sequence Diagram

Sequence diagram menggambarkan interaksi antar objek di dalam dan di sekitar sistem (termasuk pengguna, display, dan sebagainya) berupa message yang digambarkan terhadap waktu [7].

g. Framework Laravel

Laravel adalah framework untuk pengembangan website berbasis MVC yang ditulis dalam PHP yang dirancang untuk meningkatkan kualitas perangkat lunak dengan mengurangi biaya pengembangan awal dan biaya pemeliharaan, dan untuk meningkatkan pengalaman bekerja dengan aplikasi dengan menyediakan sintaks yang ekspresif, jelas dan menghemat waktu.

h. $\mathrm{MVC}$

MVC merupakan singkatan dari Model, View, dan Controller. MVC adalah suatu metode yang memisahkan data logic (Model) dari presentation logic (View) dan process logic (Controller) atau secara sederhana adalah memisahkan antara desain interface, data, dan proses [8].

i. Mean Opinion Score

Pengujian MOS (Mean Opinion Score) digunakan untuk mengetahui respon penilaian secara subjektif dari responden terhadap sistem yang dibuat berdasarkan pengamatan hasil survey [9].

\section{Metode Pengabdian Masyarakat}

Metode pelaksanaan dari kegiatan praktek kerja lapangan ini digambarkan pada diagram alir Gambar 1.

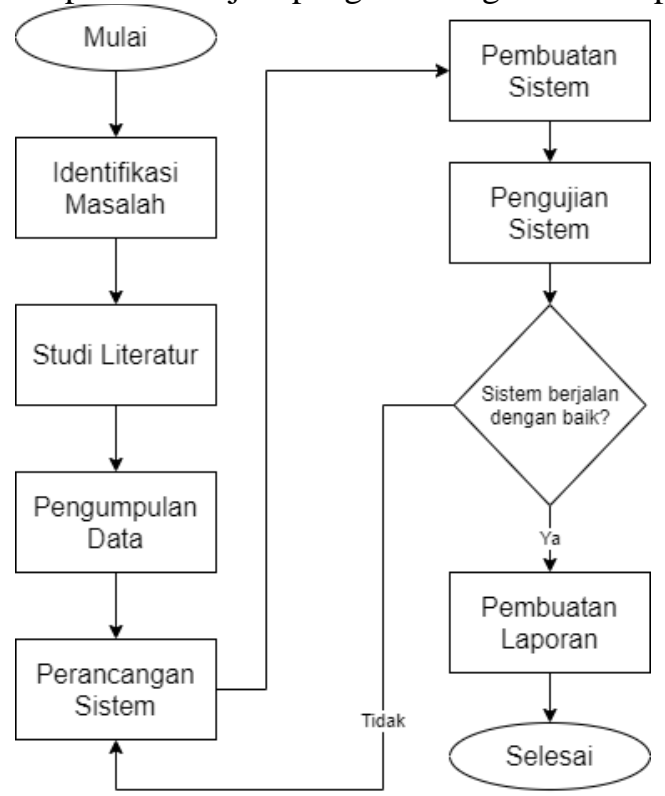

Gambar 1. Diagram alir metode pelaksanaan PKL

a. Identifikasi Masalah

Pada proses ini dilakukan identifikasi masalah pada instansi terkait, yaitu BPKAD Provinsi NTB yang akan digunakan untuk menyelesaikan kegiatan praktek kerja lapangan ini.

b. Studi Literatur

Studi literatur dilakukan untuk mengetahui bagaimana sistem informasi ini bisa berjalan dengan semestinya. Dimana dalam kasus ini penerapan framework Laravel pada sistem informasi yang akan dibangun.

c. Pengumpulan Data

Metode yang digunakan untuk pengumpulan data adalah metode kepustakaan dimana informasi yang dibutuhkan diambil dari buku dan jurnal-jurnal penelitian yang telah dilakukan sebelumnya. Pada tahap ini 
diperlukan juga komunikasi yang bertujuan untuk memahami perangkat lunak yang diharapkan oleh pengguna dan batasan perangkat lunak tersebut. Informasi ini menggunakan metode wawancara, diskusi dan survei langsung. Kemudian informasi dianalisis untuk mendapatkan data yang dibutuhkan oleh pengguna.

\subsection{Perancangan Sistem}

\subsubsection{Metode Pengembangan Sistem}

Pengembangan perangkat lunak dilakukan menggunakan model waterfall seperti pada Gambar 2. Model waterfall atau yang sering disebut model classic life cycle menunjukkan pengembangan perangkat lunak secara berurutan dan sistematis.

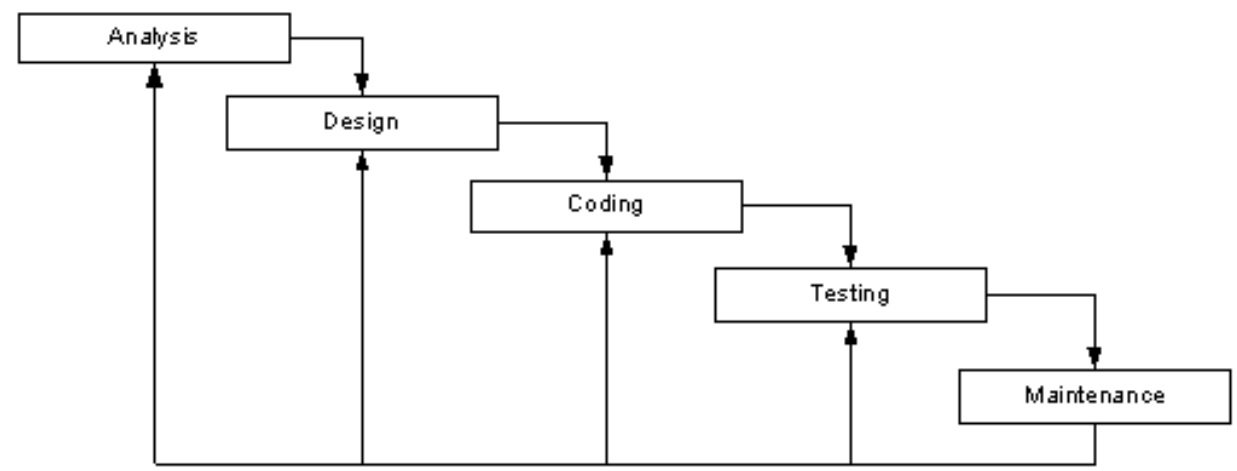

Gambar 2. Metode pengembangan sistem

\subsubsection{Use Case Diagram}

Berikut ini merupakan Use Case Diagram dari sistem manajemen aset BPKAD Provinsi NTB yang ditunjukan pada Gambar 3.

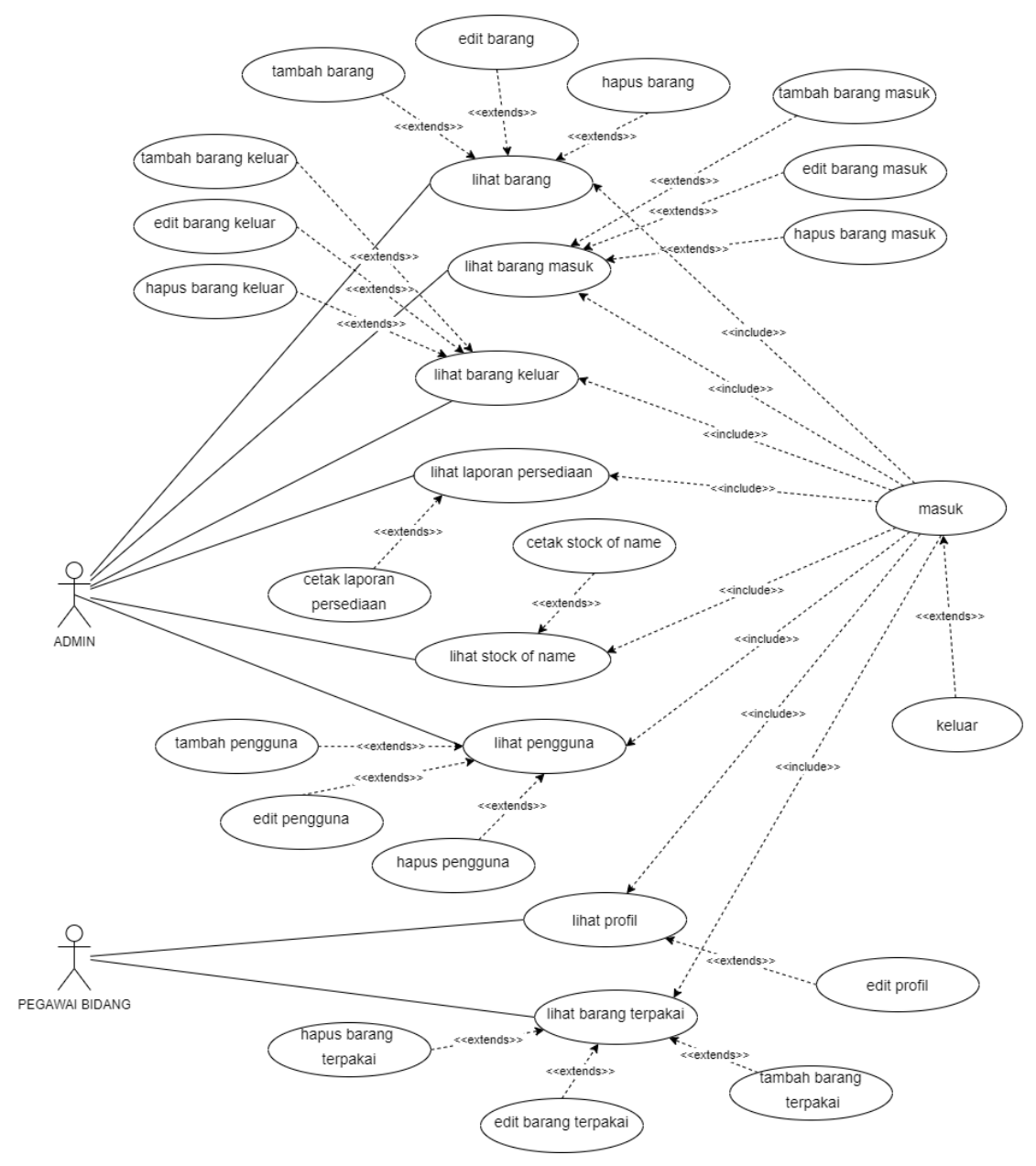


Gambar 3. Use case diagram

\subsubsection{Activity Diagram}

Berikut merupakan Activity Diagram dari manajemen aset BPKAD Provinsi NTB :

a. Proses login.

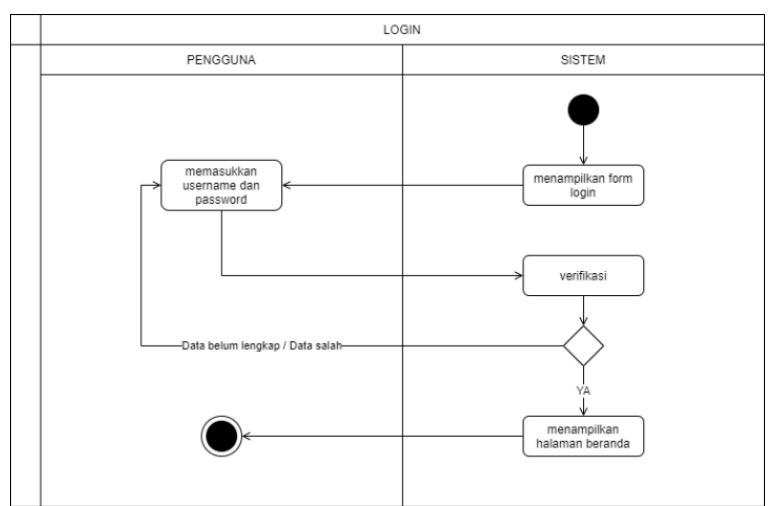

Gambar 4. Activity diagram login

Gambar 4 merupakan activity diagram dari proses login yang dimulai dari sistem menampilkan form login dimana pengguna memasukkan username dan password untuk diverifikasi. Apabila data sudah lengkap dan sudah valid maka sistem akan menampilkan halaman beranda. Apabila data tidak ditemukan atau data yang diisi salah maka pengguna harus memasukkan ulang data username dan password yang sesuai.

b. Proses menambahkan data.

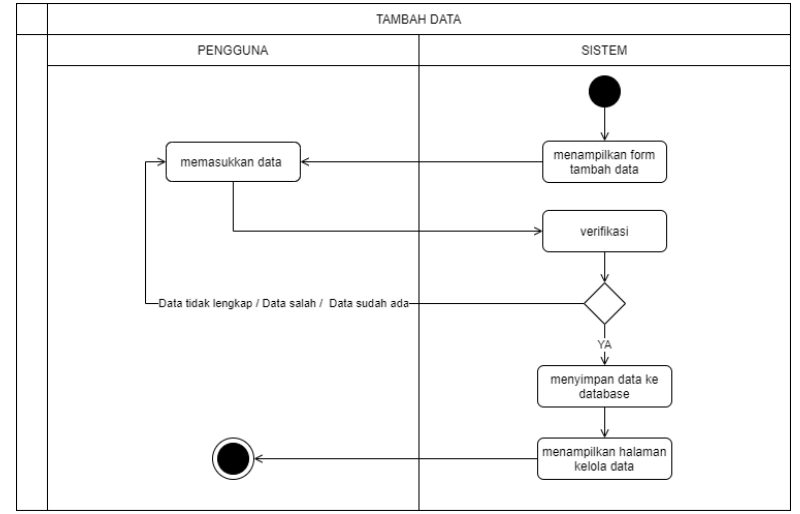

Gambar 5. Activity diagram tambah data

Gambar 5 merupakan activity diagram dari proses tambah data. Proses ini berawal dari sistem yang menampilkan form tambah data, kemudian pengguna mengisi data sesuai yang dibutuhkan untuk diverifikasi. Jika data diterima maka data akan disimpan di dalam database, selanjutnya sistem menampilkan halaman kelola data.

c. Proses mengubah data.

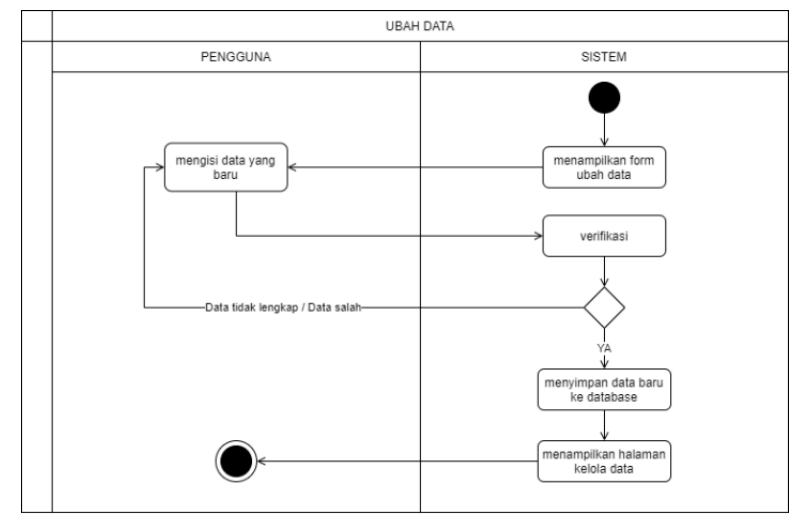

Gambar 6. Activity diagram ubah data 
Gambar 6 merupakan activity diagram dari proses ubah data. Proses ini berawal dari sistem menampilkan form ubah data, lalu pengguna mengisi data baru yang ingin diubah untuk diverifikasi. Jika data diterima, maka data akan disimpan di dalam database, selanjutnya sistem akan menampilkan halaman kelola data.

d. Proses menghapus data.

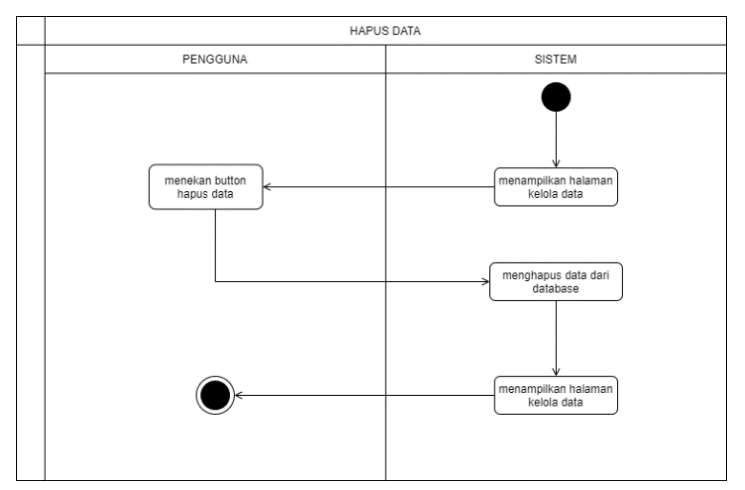

Gambar 7. Activity diagram hapus data

Gambar 7 merupakan activity diagram dari proses menghapus data. Proses ini berawal dari sistem menampilkan halaman kelola data. Pengguna menekan tombol hapus pada data yang dipilih di halaman kelola data. Setelah itu, data yang terpilih akan dihapus dari database dan sistem menampilkan halaman kelola data.

e. Proses mencetak laporan persediaan oleh admin.

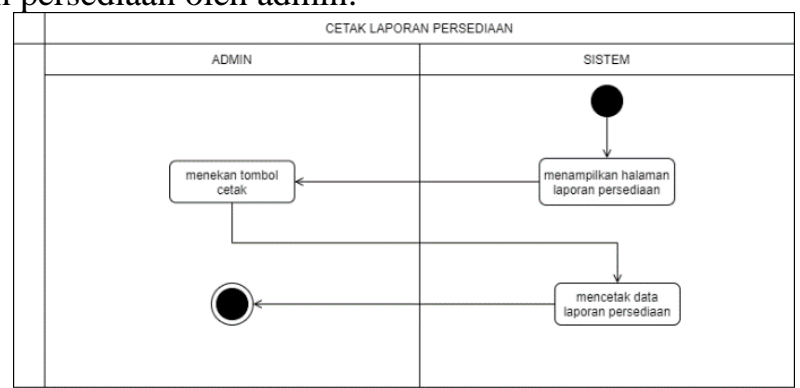

Gambar 8. Activity diagram cetak laporan persediaan oleh admin

Gambar 8 merupakan activity diagram dari proses mencetak laporan persediaan. Pengguna dapat mencetak laporan persediaan dengan menekan tombol cetak pada halaman tersebut, maka data laporan persediaan akan langsung tercetak.

f. Proses mengubah profil oleh pegawai bidang.

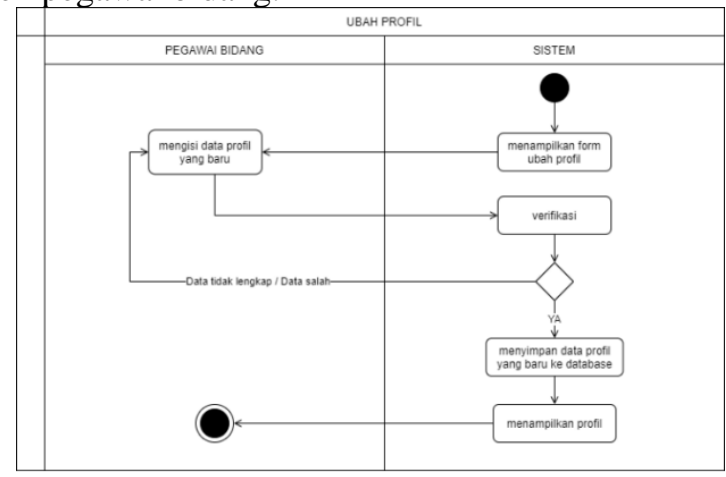

Gambar 9. Activity diagram ubah profil

Gambar 9 merupakan activity diagram dari proses mengubah profil. Aktivitas mengubah profil dapat dilakukan oleh pegawai bidang dengan sistem akan menampilkan form ubah profil. Dalam form tersebut pegawai bidang akan mengisi data yang baru seperti nama, email, username, dan password. Setelah dilakukan verifikasi kesesuaian data maka profil pegawai bidang yang baru tersebut dapat disimpan dalam database. 


\subsubsection{Class Diagram}

Berikut ini merupakan Class Diagram dari sistem manajemen aset BPKAD Provinsi NTB yang ditunjukan pada Gambar 10.

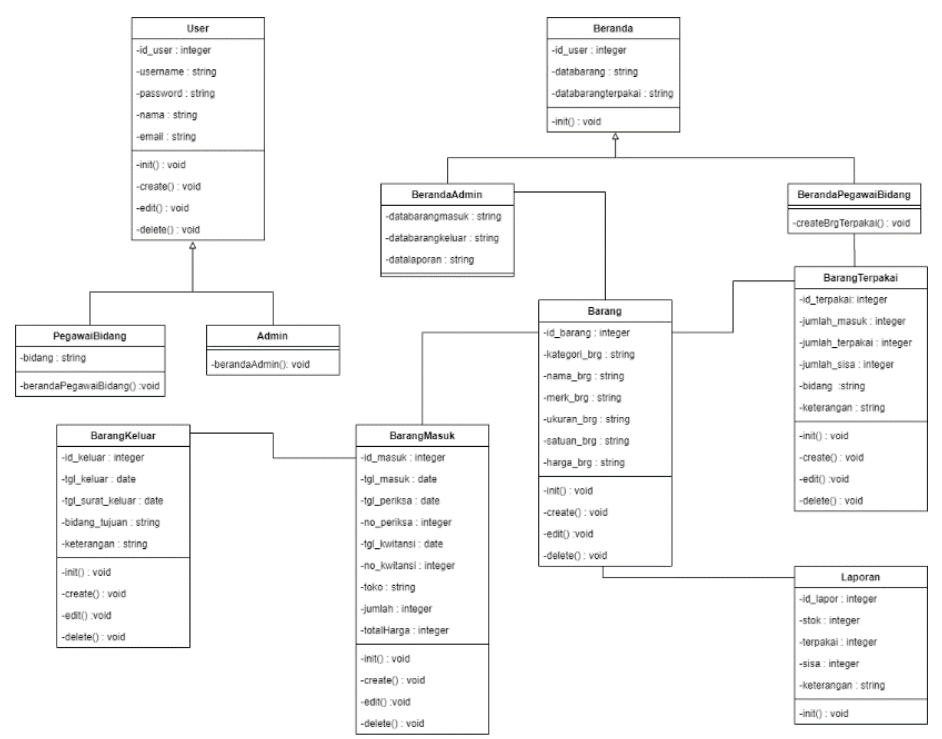

Gambar 10. Class diagram

\subsubsection{Sequence Diagram}

Berikut adalah sequence diagram dari sistem manajemen aset BPKAD Provinsi NTB:

a. Menambahkan data.

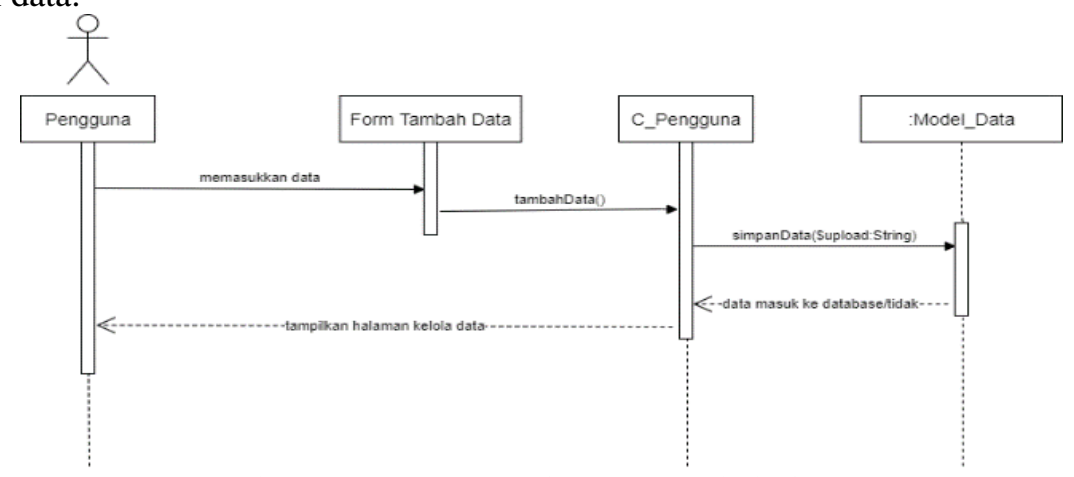

Gambar 111. Sequence diagram tambah data

Gambar 11 merupakan sequence diagram dari proses tambah data. Proses ini diawali mengisi form tambah data. Pengguna memasukkan data pemeliharaan kemudian memanggil fungsi "create ()" pada Controller Pengguna dan data yang dimasukkan dikirim pada fungsi "simpan ()" dan akan tersimpan dalam database.

b. Mengubah data.

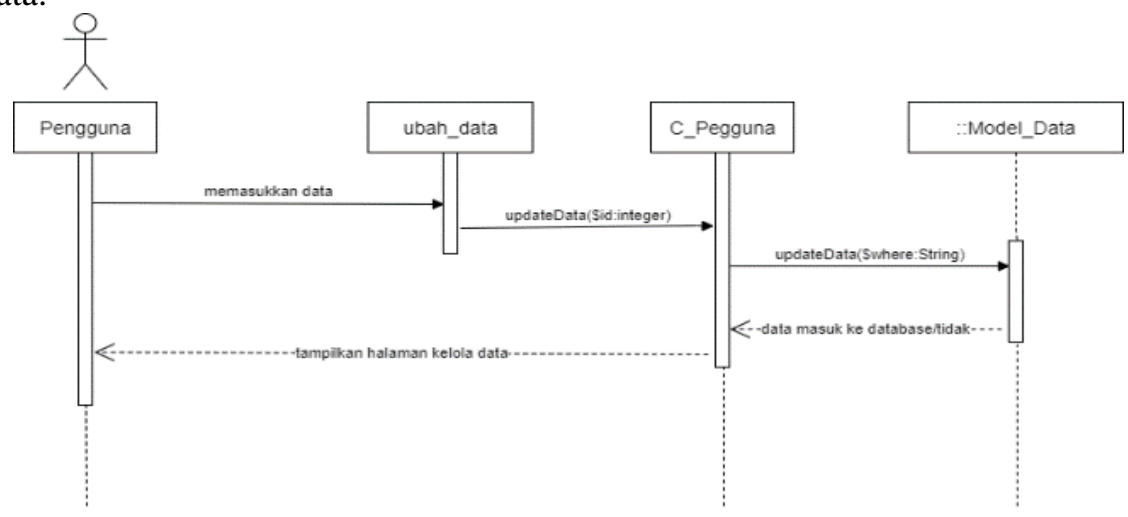

Gambar 12. Sequence diagram ubah data 
Gambar 12 merupakan sequence diagram dari proses ubah data. Proses ini diawali mengisi form ubah_data lalu memanggil fungsi "update()" pada Controller Pengguna dan data dikirim pada fungsi "updateData()" pada Model Model_Data. Jika penyimpanan data berhasil, maka akan ditampilkan halaman kelola data.

c. Menghapus data.

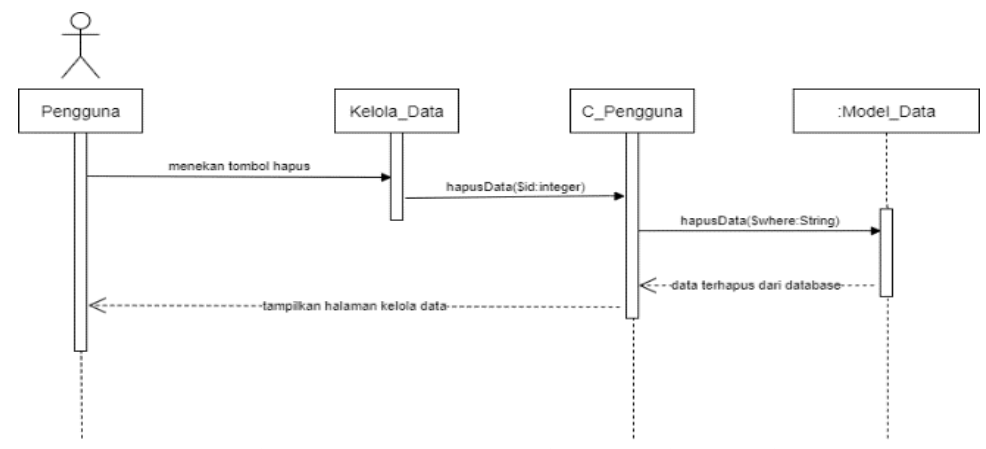

Gambar 123. Sequence diagram hapus data

Gambar 13 merupakan sequence diagram hapus data. Berawal dari pengguna menekan tombol hapus kemudian memanggil fungsi "hapus ()" pada Controller Pengguna. Data akan dihapus menggunakan fungsi "hapusData ()" pada Model Model_Data dan data akan terhapus dari database.

d. Mencetak laporan persediaan.

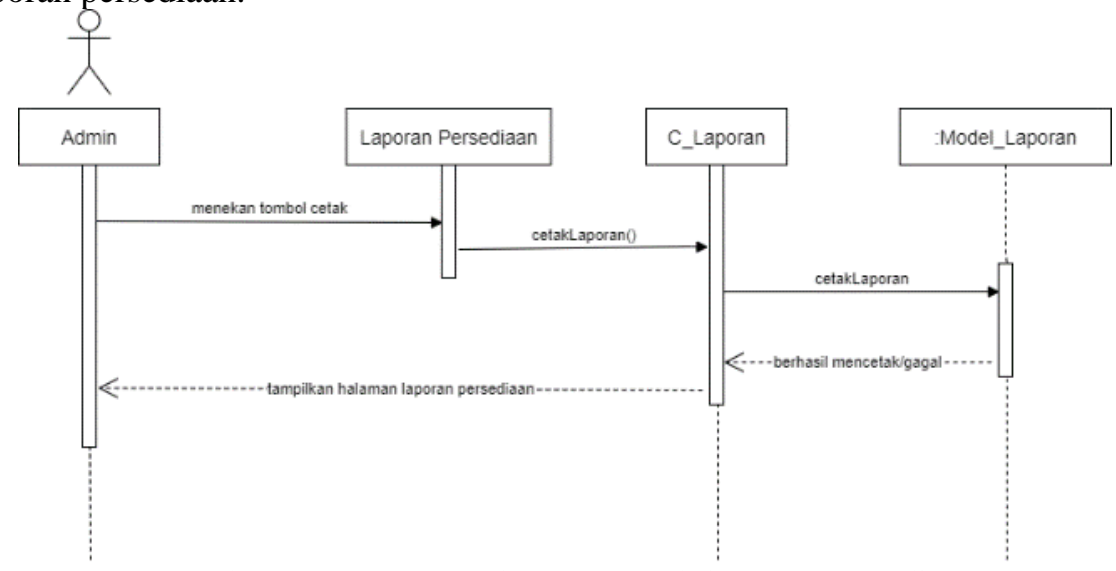

Gambar 14. Sequence diagram cetak laporan persediaan

Gambar 14 merupakan sequence diagram proses mencetak laporan persediaan. Berawal dari Admin menekan tombol cetak pada halaman laporan persediaan kemudian memanggil fungsi "cetakLaporan ()" pada Controller Laporan. Selanjutnya laporan persediaan akan tercetak dan sistem akan menampilkan kembali halaman laporan persediaan.

\subsubsection{Entity Relationship Diagram (ERD)}

Berikut pada Gambar 17 adalah ERD (Entity Relationship Diagram) dari sistem manajemen aset BPKAD Provinsi NTB yang terdiri dari 6 entitas, yaitu user, barang, barang masuk, barang keluar, barang pakai, dan laporan.

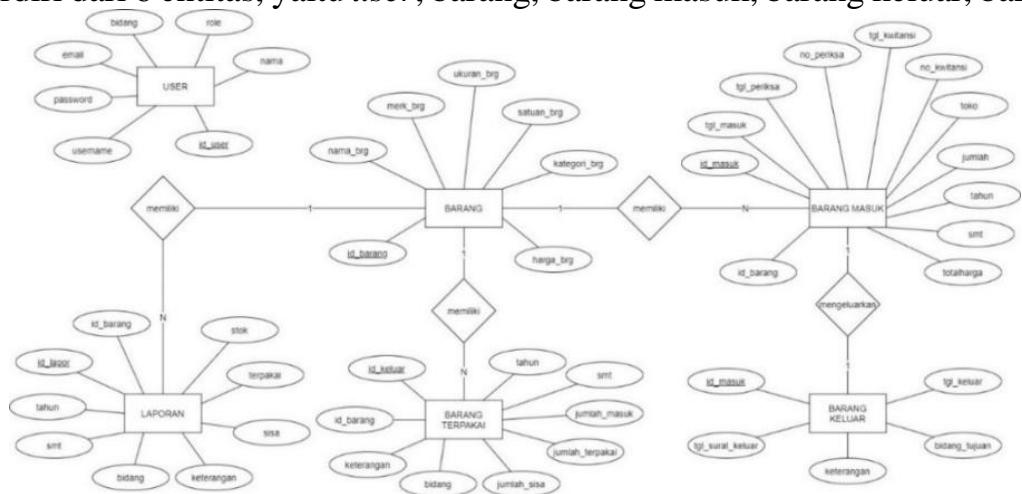

Gambar 15. ERD sistem informasi manajemen aset 


\section{Hasil dan Pembahasan}

\subsection{Pembuatan Sistem}

\subsubsection{Implementasi Interface Sistem}

Berikut adalah implementasi tampilan (interface) program dari sistem informasi manajemen aset BPKAD :

a. Halaman login.

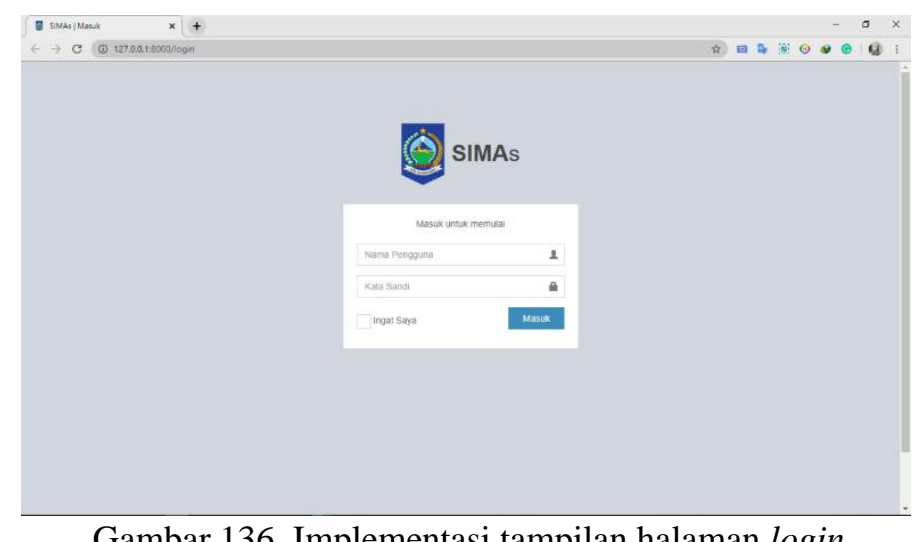

Gambar 136. Implementasi tampilan halaman login

Gambar 16 merupakan implementasi dari halaman login yang digunakan pengguna untuk masuk ke dalam sistem.

b. Halaman beranda.

1. Bagi admin.

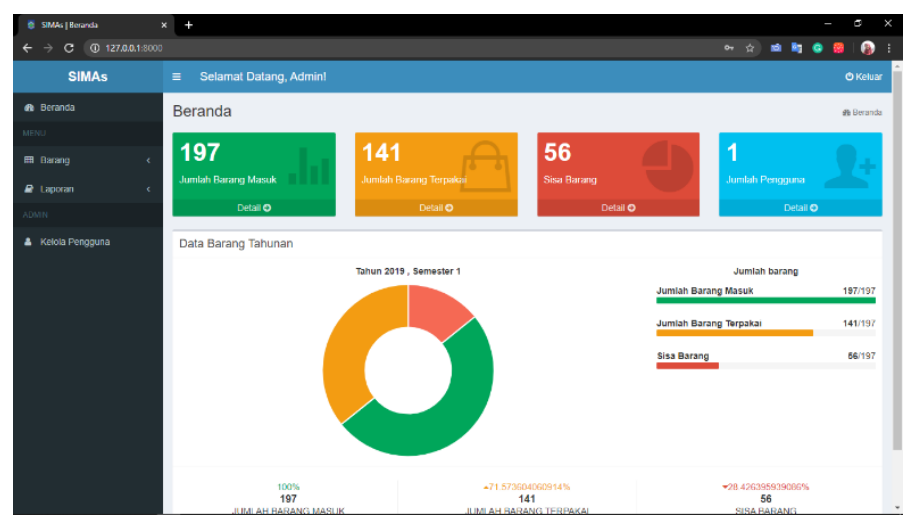

Gambar 17. Implementasi tampilan halaman beranda admin

Pada Gambar 17 merupakan implementasi dari halaman beranda yang akan dijumpai admin ketika pertama kali masuk ke dalam sistem.

2. Bagi pegawai bidang.

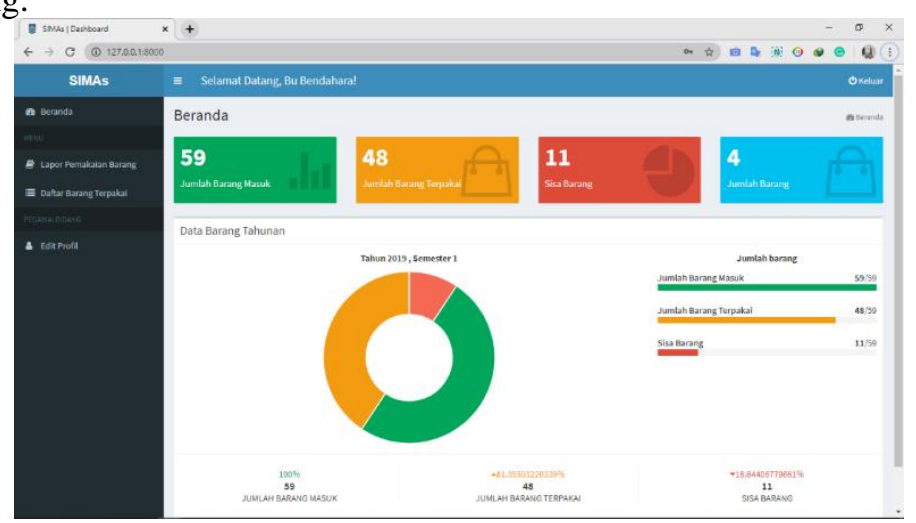

Gambar18. Implementasi tampilan halaman beranda pegawai bidang

Pada Gambar 18 merupakan implementasi dari halaman beranda yang akan dijumpai pegawai bidang ketika pertama kali masuk ke dalam sistem. 
c. Halaman daftar barang bagi admin.

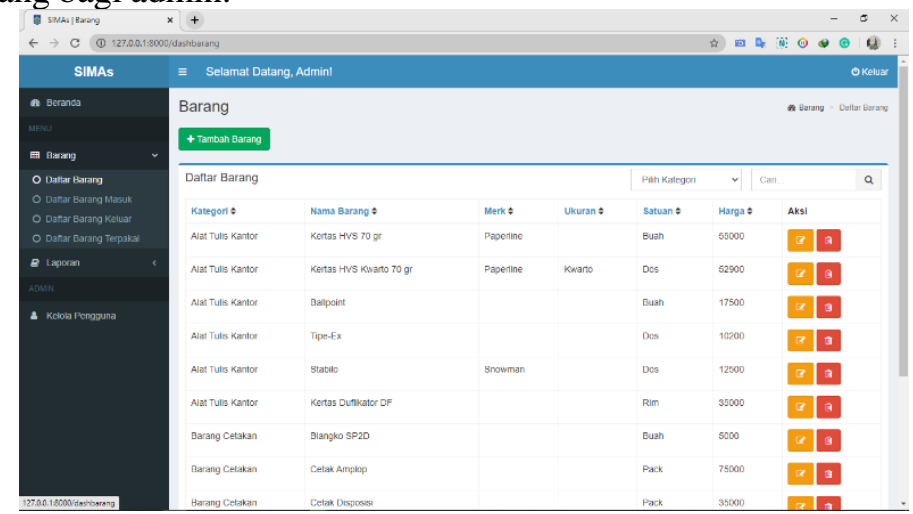

Gambar 19. Implementasi tampilan halaman daftar barang admin

Pada Gambar 19 merupakan implementasi dari halaman daftar barang yang berisi informasi tentang barang dan tombol cari untuk melakukan pencarian barang. Pada halaman daftar barang juga dilengkapi dengan tombol tambah, hapus, dan edit data barang.

d. Halaman menambahkan data barang bagi admin.

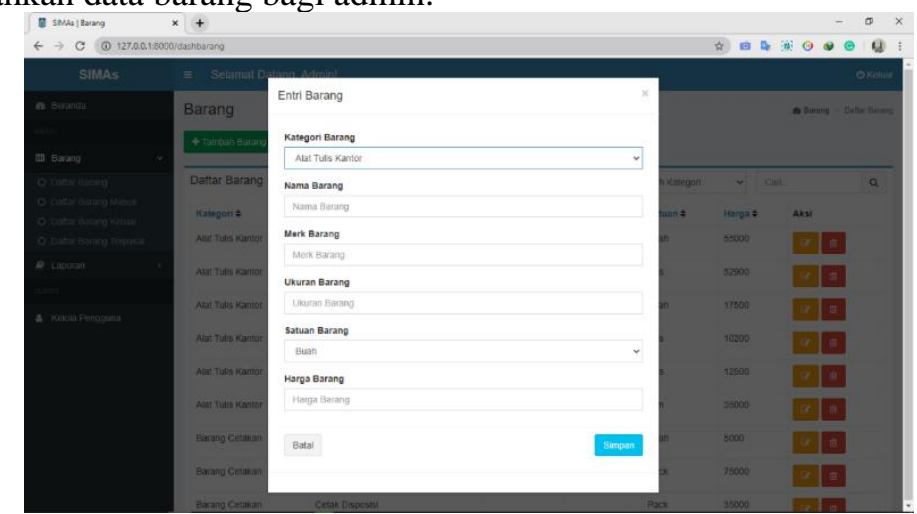

Gambar 20. Implementasi tampilan halaman isi data barang admin

Pada Gambar 20 merupakan implementasi tampilan dari halaman isi data barang bagi admin.

e. Halaman daftar barang terpakai.

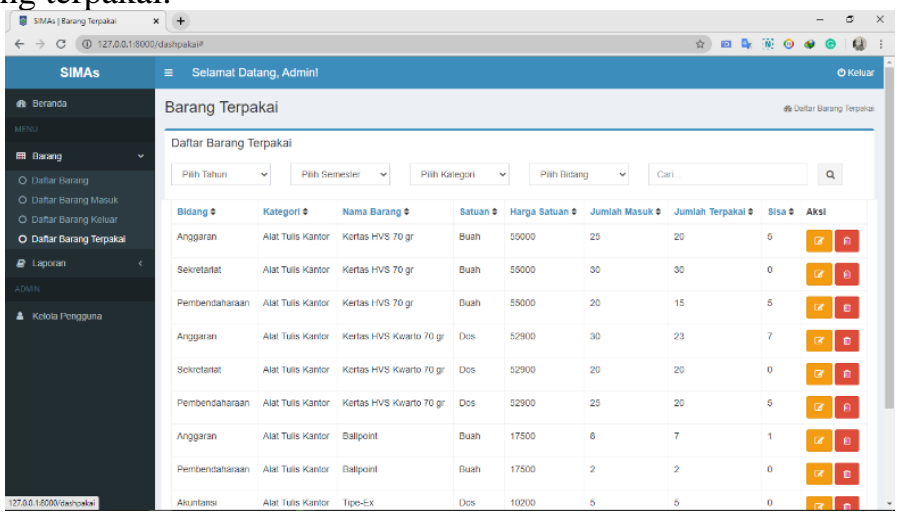

Gambar 21. Implementasi tampilan halaman daftar barang terpakai admin

Pada Gambar 21 merupakan implementasi dari halaman daftar barang terpakai yang berisi informasi tentang barang terpakai dan tombol cari untuk melakukan pencarian barang terpakai. Pada halaman daftar barang terpakai bagi admin juga dilengkapi dengan tombol hapus, dan edit data barang. 
f. Halaman cetak laporan persediaan bagi admin.

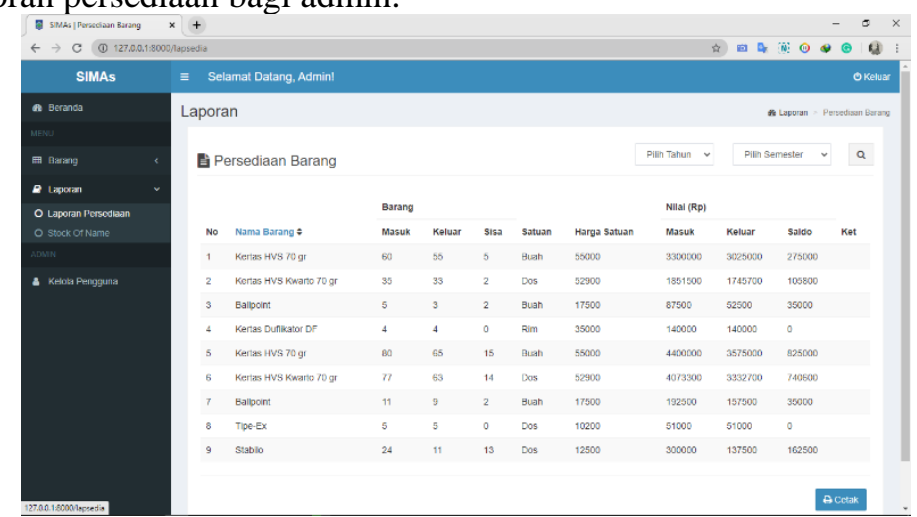

Gambar 22. Implementasi tampilan halaman laporan persediaan admin

Pada Gambar 22 merupakan implementasi dari halaman laporan persediaan dan tombol cari untuk melakukan pencarian.

\subsection{Pengujian Sistem}

Pengujian sistem dilakukan dengan mengujinya kepada pihak BPKAD Provinsi NTB dimana aspek pengujian sistem adalah tampilan sistem dan performa sistem. Pengujian sistem dilakukan dengan metode MOS (Mean Opinion Score) untuk mengetahui respon dari responden terhadap sistem yang dibuat. Adapun yang akan dinilai pada pengujian ini adalah dari segi kemudahan penggunaan sistem dan tampilan sistem. yaitu:

Pengujian dilakukan terhadap 5 responden dari pihak BPKAD Provinsi NTB yang terdiri dari 6 pertanyaan,

a. Sistem mudah digunakan?

b. Sistem memiliki kecocokan font, warna, dan style di setiap halaman?

c. Navigasi pada sistem cukup sederhana dan mudah digunakan?

d. Fungsi tiap fitur sudah sangat jelas?

e. Fitur-fitur pada sistem sudah sesuai dengan kebutuhan instansi?

f. Sistem mempermudah pekerjaan pegawai?

Dari pertanyaan tersebut, responden diminta untuk menjawab dengan beberapa pilihan, yaitu:
a. SS = Sangat Setuju.
b. $\mathrm{S}=$ Setuju.
c. CS = Cukup Setuju.
d. TS = Tidak Setuju.
e. STS = Sangat Tidak Setuju.

Adapun grafik hasil perhitungan MOS digambarkan dengan grafik pada Gambar 23.

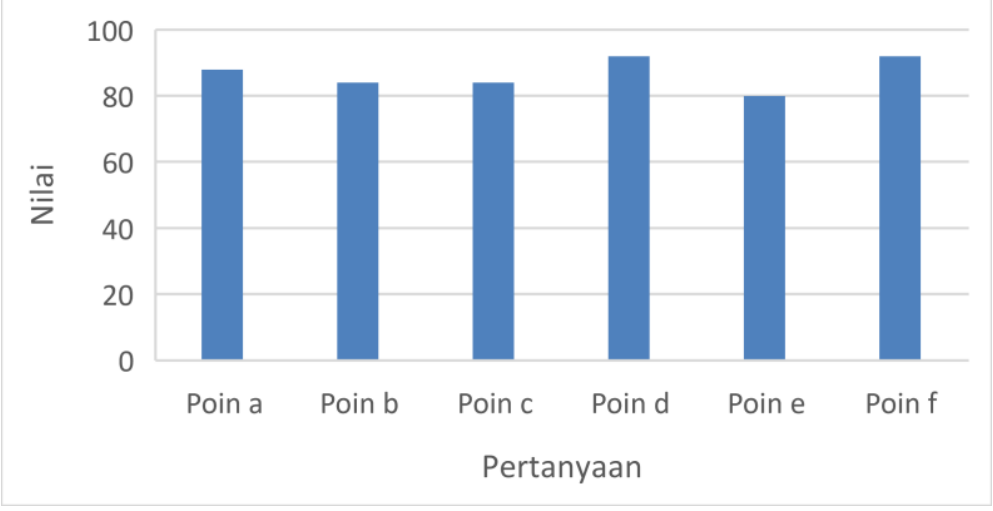

Gambar 23. Grafik hasil jawaban responden

a. Pengujian User Interface dan User Experience.

Pengujian User Interface dan User Experience pada sistem diwakilkan oleh pertanyaan poin a, b, dan c pada sistem. Dimana didapatkan nilai MOS $=88$ dari interval 100 untuk kemudahan penggunaan sistem, nilai MOS = 84 dari interval 100 untuk kecocokan font, warna, dan style di setiap halaman, dan nilai MOS = 84 
dari interval 100 untuk navigasi sistem yang sederhana dan mudah digunakan. Maka dari itu, untuk menghitung hasil rata-rata dari pengujian User Interface dan User Experience dari sistem dilakukan penjumlahan hasil dari tiap poin pertanyaan lalu dibagi jumlah poin pertanyaan sehingga didapatkan hasil pengujian User Interface dan User Experience sebesar 85.34\%.

b. Pengujian performa sistem.

Pengujian performa pada sistem diwakilkan oleh pertanyaan poin d, e, dan $\mathrm{f}$ pada sistem. Dimana didapatkan nilai MOS $=92$ dari interval 100 untuk kejelasan fungsi dari tiap fitur, nilai MOS $=80$ dari interval 100 untuk kesesuaian fitur pada sistem dengan kebutuhan instansi, dan nilai MOS = 92 dari interval 100 untuk sistem yang memudahkan pekerjaan pegawai. Maka dari itu, untuk menghitung hasil rata-rata dari pengujian performa dari sistem dilakukan penjumlahan hasil dari tiap poin pertanyaan lalu dibagi jumlah poin pertanyaan sehingga didapatkan hasil pengujian performa sistem sebesar $88 \%$.

Berdasarkan hasil pengujian MOS yang dilakukan oleh 5 orang responden, pengujian yang dilakukan pada pihak BPKAD Provinsi NTB menghasilkan nilai MOS $=86,67 \%$ yang menunjukkan bahwa Sistem Informasi Manajemen Aset pada BPKAD Provinsi NTB telah berjalan dengan baik.

\section{KESIMPULAN DAN SARAN}

\subsection{Kesimpulan}

Berdasarkan hasil Praktek Kerja Lapangan di BPKAD Provinsi NTB berupa sistem informasi manajemen aset berbasis web menggunakan framework Laravel, didapatkan kesimpulan sebagai berikut :

a. Sistem Informasi Manajemen Aset pada BPKAD Provinsi NTB telah berjalan dengan baik berdasarkan hasil pengujian yang dilakukan pada pihak BPKAD yang menghasilkan nilai Mean Opinion Score sebesar $86,67 \%$.

b. Pengujian proses yang ada dan performa dari Sistem Informasi Manajemen Aset pada BPKAD Provinsi NTB sudah sesuai dengan kebutuhan instansi dengan hasil persentase jawaban kuesioner sebesar 88\%.

c. Pengujian User Interface dan User Experience dari Sistem Informasi Manajemen Aset pada BPKAD Provinsi NTB menunjukkan tampilan sistem menarik dan sistem mudah digunakan oleh pengguna dengan persentase jawaban kuesioner sebesar $85,34 \%$.

\subsection{Saran}

Adapun saran yang dapat diberikan penulis agar Sistem Informasi Manajemen Aset pada BPKAD Provinsi NTB ini menjadi lebih baik di masa yang akan datang yaitu dalam pengembangan selanjutnya, diharapkan sistem informasi ini dapat terintegrasi dengan sistem berbasis mobile untuk memudahkan pengisian data persediaan barang yang terdapat pada BPKAD Provinsi NTB.

\section{DAFTAR PUSTAKa}

[1] J. Riyanto, "Rancang Bangun Sistem Informasi Manajemen Aset Pada Universitas Pamulang Berbasis WRiyanto, J. (2019). Rancang Bangun Sistem Informasi Manajemen Aset Pada Universitas Pamulang Berbasis Web. Jurnal Informatika Universitas Pamulang, 4(1), 9. https://doi.org," J. Inform. Univ. Pamulang, vol. 4, no. 1, pp. 9-15, 2019, doi: 10.32493/informatika.v4i1.2406.

[2] Z. Efendy, I. E. Putra, and R. Saputra, "Asset Rental Information System and Web-Based Facilities At Andalas University," J. Terap. Teknol. Inf., vol. 2, no. 2, pp. 135-146, 2018, doi: 10.21460/jutei.2018.22.103.

[3] F. S. B, M. A. Safi'ie, and O. D. W. A.S.T, "Implementasi Sistem Informasi Akademik Berbasis Web Menggunakan Framework Laravel,” J. Transform., vol. 12, no. 1, pp. 46-50, 2017.

[4] F. Luthfi, "Penggunaan Framework Laravel Dalam Rancang Bangun Modul Back-End Artikel Website Bisnisbisnis.ID,” JISKA (Jurnal Inform. Sunan Kalijaga), vol. 2, no. 1, pp. 34-41, 2017, doi: 10.14421/jiska.2017.21-05.

[5] Yakub, Pengantar Sistem Informasi. Yogyakarta: Graha Ilmu, 2012.

[6] M. R. Pratama, B. Pangayow, and M. Si, "Pengaruh Manajemen Aset Terhadap Optimalisasi," vol. 11, no. November, pp. 33-51, 2016.

[7] D. Widodo, Menggunakan UML. Bandung: Informatika, 2011.

[8] Prijambodo, Out of The Box Koperasi tantangan perubahan kini dan masa depan. Yogyakarta: Ahmed Ghoseen A, 2018.

[9] Z. Rahmiati, I. G. P. S. Wijaya, and B. Irmawati, "The Analysis System Students Satisfaction Level Toward Teaching and Learning Process in PSTI Unram Using Service Quality Method," JTIKA, vol. 1, no. 1, pp. 3140, 2019. 